\title{
Динамика показателей поглотительной способности почв после пирогенного воздействия
}

\author{
(C) 2019 Горбунова Ю.С., Девятова Т.А. \\ ФГБОУ ВО «Воронежский государственный университет», Воронеж
}

Поступила в редакцию 22.07.2019 г.

DOI: 10.17308/sorpchrom.2019.19/2235

Статья посвящена мониторингу показателей почвенного поглотительного комплекса (ППК) дерново-лесной глеево-элювиальной почвы подвергшейся пожару в 2010 году. В 0-10 см слое произошло уменьшение в содержании илистой фракции на $3.25 \%$, уменьшилось содержание средней пыли на $0.07 \%$ и мелкой пыли - на $0.48 \%$.Установлено, что в первый год, после лесного пожара, повысилось значение $\mathrm{pH}_{\mathrm{H} 2 \mathrm{O}}$ почвенного раствора с 5.21 до 5.93. В 2018 году реакция среды возвращается к исходному значению и составляет 5.34. Гидролитическая кислотность снизилась с 5.08 до 3.14 [ммоль (экв.)/100 г почвы]. Произошло снижение в ППК содержания суммы обменных оснований с 8.99 до 7.90 [ммоль (экв)/100 г почвы]. С 2011 по 2018 год произошло их увеличение с 7.90 до 8.27.

Ключевые слова: поглотительная способность почв, дерново-лесная глеево-элювиальная почва, лесной пожар, гранулометрический состав.

\section{Dynamics of soil absorption capacity after pyrogenic impacts}

\author{
(C) 2019 Gorbunova Yu.S., Devyatova T.A. \\ Voronezh state university, Voronezh
}

\begin{abstract}
The dynamics of SAC is characterized by such indicators as the sum of absorbed bases, the cation exchange capacity and the degree of soil saturation with bases. Also important is the reaction of the soil environment, which has a huge impact on the growth and development of plants.

Objective: to identify the dynamics of SAC indices in sod-forest gley-eluvial sandy soils after a forest fire. Tasks: inception of soil cuts and their morphological description; determination of the main physicochemical and physical parameters studied according to generally accepted methods; variation-statistical processing of the results obtained using Box Plot and Microsoft Excel programs and their comparative analysis.

The actual material on the basis of which the article was written, obtained as a result of comprehensive studies and the physicochemical composition of the soils of the Central Chernozem region, conducted in 2011-2018. The objects of research are the soils: sod-forest gley-eluvial sandy sand (the biocenter of the VSU «Venevitinovo», Voronezh Region).

The dynamics of the SAC of sod-forest soils is associated with their low buffering capacity and the degree of soil saturation with bases. According to the results of the study after a forest fire, the content of exchangeable calcium and magnesium cations decreased by $8.7 \%$ compared with background soils. Compared to 2011, the content of exchange cations in 2018 increased slightly. This phenomenon is due to the fact that sod-forest soils have a low ability to resist changes in the environment and low effective fertility, which is determined by generic and species traits, the most important of which are humus content, particle size distribution, physico-chemical properties and thickness of the parent rock.
\end{abstract} distribution.

Keywords: absorbing ability of soils, sod-forest gley-eluvial sandy sand, forest fire, particle size 


\section{Введение}

Совокупность соединений, проявляющих способность к обменным реакциям, К.К. Гедройц (1935) назвал почвенным поглощающим комплексом (ППК), который характеризуется с физической стороны как совокупность мелкораздробленных почвенных соединений, с химической - как комплекс нерастворимых в воде алюмосиликатных, органических и органо-минеральных соединений и что, в общем, определяет его как высокодисперсную часть, совпадающую с коллоидной частью почвы (0.2-0.001 мкм) и включающей предколлоидную фракцию (0.2-1 мкм). Основным механизмом обменной поглотительной способности почв является процесс сорбции. Природа и состав ППК связаны с типом почвообразования. Состояние ППК - один из основных факторов, определяющих уровень плодородия любой почвы, от которого зависят питательный режим почвы, ее химические, физические, биологические и другие свойства. Без их учета не могут быть успешно решены экологические проблемы природопользования [1].

Динамика ППК характеризуется такими показателями, как сумма поглощенных оснований, емкость катионного обмена и степень насыщенности почв основаниями. Важное значение имеет и реакция почвенной среды, оказывающая огромное влияние на рост и развитие растений, которая также обуславливает скорость и направленность протекающих в почве химических и биохимических процессов [2].

Изучению истории пожаров посвящено огромное число работ (Мелехов, 1939,1947, 1948; Корчагин, 1954; Вакуров, 1975; Zackrisson, 1977; Barnes, 1984; Engelmark, 1993; Громцев, 1993; Niklasson, 2000; Axelsson, Ostlund, 2001; Коршунов, 2002 и др.). В работах M. Schmidt и C. Hardy (2001) даны обзоры современных методов, применяемых при исследовании пирогенных углей [3-20]. К сожалению данных, которые затрагивали бы динамику ППК после пирогенного воздействия крайне мало.

Цель работы - выявление динамики показателей ППК в дерново-лесных глеево-элювиальных песчаных почвах после лесного пожара. Задачи: заложение почвенных разрезов и их морфологическое описание; определение основных физикохимических и физических показателей изучаемых почв по общепринятым методикам [21]; вариационно-статистическая обработка полученных результатов с использованием программ Box Plot и Microsoft Excel и их сравнительный анализ.

\section{Теоретическая часть}

В обменной форме находятся многие макро- и микроэлементы минерального питания растений. Наиболее важны для диагностики процессов почвообразования и плодородия почв обменные катионы почвенного поглощающего комплекса: $\mathrm{Ca}^{2+}$, $\mathrm{Mg}^{2+}, \mathrm{Na}^{+}, \mathrm{H}^{+}, \mathrm{Al}^{3+}$.

Обменный $\mathrm{Ca}^{2+}$ способствует образованию водопрочных агрегатов, с ним связана нейтральная реакция почвы.

Большое содержание в ППК обменного $\mathrm{H}^{+}$обусловливает кислую реакцию почвы. На физико-химической поглотительной способности почв основаны некоторые виды мелиорации: известкование кислых почв, гипсование солонцов.

Важной характеристикой ППК является степень насыщенности основаниями - суммарное количество обменных катионов $\mathrm{Ca}^{2+}$ и $\mathrm{Mg}^{2+}$, выраженное в процентах от емкости поглощения. По степени насыщенности основаниями определяют потребность почвы в известковании: 


\section{Эксперимент}

Фактический материал, на основании которого написана статья, получен в результате комплексных исследований физического и физико-химического состава почв Центрально-Черноземного региона, проведенных в 2011-2018 годах. Объектами исследований являются почвы: дерново-лесные глеево-элювиальные песчаные (биоцентр ВГУ «Веневитиново» (Усманский бор) Воронежской области).

Почвенные образцы отбирались в течение восьми лет (2011-2018) на территориях подвергшихся пирогенному воздействию в 2010 году. Было заложено 9 прикопок в березняке. Из прикопок отбор проводился в динамике, трижды в год (май, июль, октябрь), послойно до глубины 40-50 см. На фоновых почвах, не подвергшихся пирогенному воздействию, был заложен один полнопрофильный разрез, вскрывающий почвообразующую породу. Почвенные образцы отбирались послойно (0-10, 10-20, 20-30...80-90 см), согласно ГОСТ [21]. По общепринятым методикам были проведены следующие виды анализов: гранулометрический состав почвы определялся методом пипетки с обработкой пирофосфатом натрия, обменные катионы кальция и магния по Гедройцу, гидролитическая кислотность по Каппену; рН водной суспензии потенциометрическим методом.

Вариационно-статистическая обработка полученных данных проводилась по Е.А. Дмитриеву (1972), Б.А. Доспехову (1979) и с использованием программы Microsoft Excel. Графики выполнены с помощью программы Box Plot и Microsoft Excel $[22,23]$.

Достоверность результатов исследований обеспечена применением современных методов исследований, большим объемом экспериментального материала, хорошей воспроизводимостью анализов, применением методов математической статистики с оценкой точности и достоверности полученных данных.

\section{Обсуждение результатов}

По данным Милькова Ф.Н. вторая и первая надпойменные террасы образованы водно-ледниковыми потоками валдайского оледенения, отложившего аллювиально-делювиальные осадки. Эти отложения представлены в границах Усманского бора наносами легкого гранулометрического состава. Kawahigashi et al. B 2011 выявлено, что в первую очередь при пожарах происходит изменение морфологических свойств, кислотности, гранулометрического состава почв. Галощапова и Калиненко в своей работе (2012) исследовали почвы гарей, установили, что происходит возрастание дневных максимумов температур на 5-7 $\mathrm{C}$ [5].

Согласно исследованиям Mataix-Solera et al. в почве пройденной пожаром различия в содержании гранулометрических фракций, по сравнению с условным фоном, наблюдаются в возрастании наиболее крупной фракции 1-0.25, при некотором уменьшении доли фракции мелкого песка. Вероятно, это может быть связано с процессами цементации и сцепления агрегатов, которое происходит после пожаров [12]. Кроме этого, нельзя исключать пространственную неоднородность распределения песчаных фракций на рассматриваемых участках. При этом нижние подгоризонты подстилок практически не отличаются от условно-фоновых участков.

Иванова С.А. установила, что направленность изменений зависит от минералогического состава илистой фракции: в почвах, где преобладающим минералом является монтмориллонит, понижение $\mathrm{pH}$ приводит к уменьшению содержания обменных катионов и понижению селективности почв к ионам $\mathrm{Ca}^{2+}$, тогда как в темнокаштановой почве, в составе илистой фракции которой преобладает иллит-смектит, 
сумма обменных катионов и селективность к $\mathrm{Ca}^{2+}$-ионам возрастает при понижении $\mathrm{pH}$.

По результатам исследования Ивановой С.А. сумма обменных катионов чувствительна к изменениям концентрации раствора: понижение ионной силы раствора приводило к уменьшению суммы обменных катионов [24]. Чуян О.Г. выявил существенную взаимосвязь величин емкости катионного обмена, суммы обменных оснований, гидролитической кислотности почв с величинами показателей, определяющих основные характеристики почвенного поглощающего комплекса (содержанием физической глины (<0.01 мм), гумуса и обменной кислотности $\mathrm{pH})$. Разработаны дополнительные показатели для оценки как абсолютных величин компонентов ППК, так и их изменений в зависимости от кислотности почвы [25].

Нами установлено, что мелкий песок является преобладающей фракцией в исследуемых дерново-лесных глеево-элювиальных, который в среднем составляет $53.0 \%$. Затем в порядке убывания следуют фракции крупного и среднего песка $31.1 \%$ и крупной пыли 6.84 \% и наименьшее содержание приходится на мелкую пыль $1.12 \%$. Чуть большее количество приходится на фракцию средней пыли 3.62 и ила $4.72 \%$ (рис. 1, 2). При движении вниз по профилю происходит облегчение гранулометрического состава (табл. 1). Данное положение объясняется тем, что изучаемые почвы образовались на почвообразующей породе легкого гранулометрического состава. По данным гранулометрического состава исследуемые почвы являются песчаными. В результате пирогенного воздействия в 0-10 см слое произошло изменение в сторону уменьшения илистой фракции на $3.25 \%$, что в относительных процентах составляет $68.9 \%$ относительно фоновых почв (рис. 1). Уменьшилось содержание средней пыли на $0.07 \%$, что в относительных процентах составляет $1.93 \%$ и мелкой пыли- на $0.48 \%$, что в относительных процентах составляет $42.9 \%$. Содержание фракции крупного и среднего песка увеличилось - на $1.60 \%$, что в относительных процентах составляет $5.15 \%$ соответственно. Под березняком на $3.60 \%$ увеличилось содержание фракции мелкого песка в пирогенных почвах в сравнении с эталонными, что в относительных процентах составляет $6.84 \%$ (рис. 1,2 ).

Таблица 1. Гранулометрический состав фоновых и пирогенных дерново-лесных глеево-элювиальных песчаных почв на древнеаллювиальных отложениях (\%)

\begin{tabular}{|c|c|c|c|c|c|c|c|}
\hline \multirow{2}{*}{$\begin{array}{c}\text { Глубина, } \\
\text { см }\end{array}$} & $\begin{array}{c}1-0.25 \\
\text { крупный и } \\
\text { средний } \\
\text { песок }\end{array}$ & $\begin{array}{c}0.25- \\
0.05 \\
\text { мелкий } \\
\text { песок }\end{array}$ & $\begin{array}{c}0.05-0.01 \\
\text { крупная } \\
\text { пыль }\end{array}$ & $\begin{array}{c}0.01- \\
0.005 \\
\text { средняя } \\
\text { пыль }\end{array}$ & $\begin{array}{c}0.005- \\
0.001 \\
\text { мелкая } \\
\text { пыль }\end{array}$ & $\begin{array}{c}<0.001 \\
\text { ил }\end{array}$ & $\begin{array}{c}<0.01 \text { физи- } \\
\text { ческая глина }\end{array}$ \\
\hline \multicolumn{8}{|c|}{ Фоновый участок } \\
\hline $0-5$ & 31.1 & 52.6 & 6.84 & 3.62 & 1.12 & 4.72 & 9.46 \\
\hline $5-15$ & 39.7 & 47.7 & 3.68 & 2.66 & 2.07 & 4.19 & 8.92 \\
\hline $15-25$ & 38.2 & 52.0 & 2.42 & 1.90 & 0.95 & 4.53 & 7.38 \\
\hline \multicolumn{7}{|c|}{ Пирогенный участок } \\
\hline $0-5$ & 32.7 & 56.2 & 5.44 & 3.55 & 0.64 & 1.47 & 5.66 \\
\hline $5-15$ & 39.9 & 48.5 & 3.57 & 2.62 & 1.88 & 3.53 & 8.03 \\
\hline $15-25$ & 38.3 & 52.2 & 2.24 & 1.86 & 0.93 & 4.47 & 7.26 \\
\hline
\end{tabular}

Таким образом, в дерново-лесных почвах после лесного пожара в верхнем 0-5 см слое происходит облегчение гранулометрического состава из-за сгорания цементирующего органического материала и спекания фракций ила и мелкой пыли, 
что по данным Giovannini G. et al., 1990 связано с дегидратацией геля, которая происходит при температуре более $220^{\circ} \mathrm{C}[20]$.

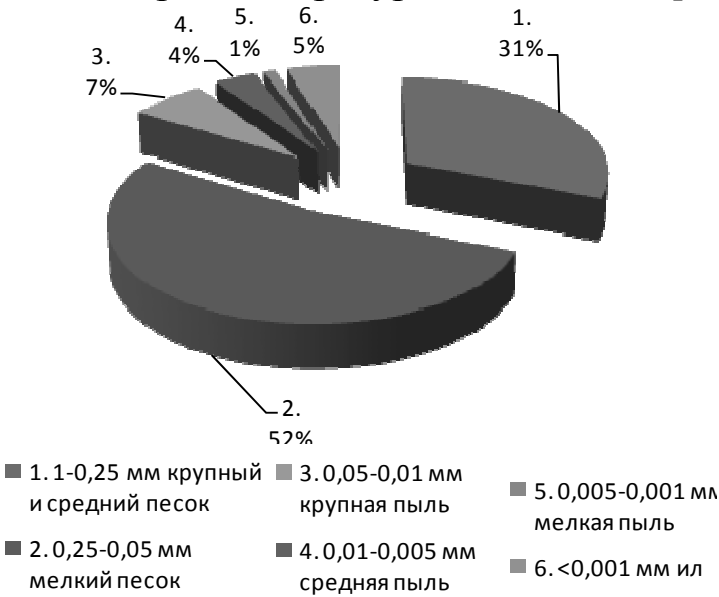

Рис. 1. Процентное соотношение различных фракций в дерново-лесных почв

(фоновый участок) в слое $0-5$ см

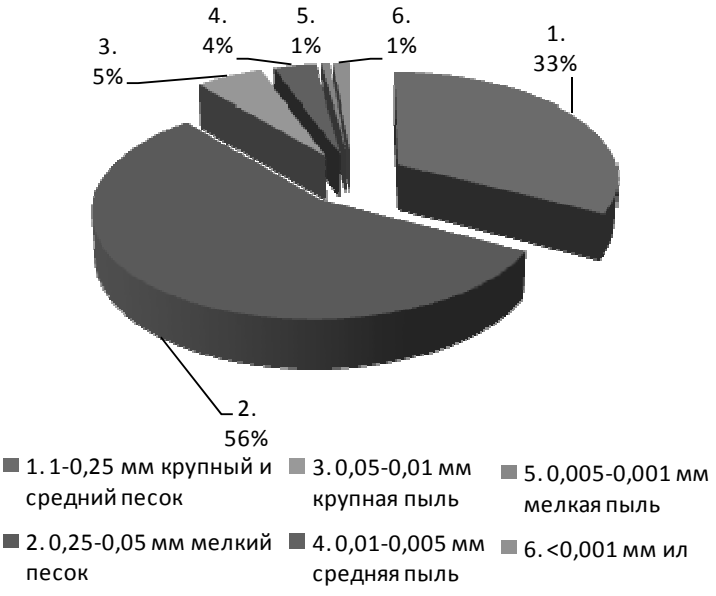

Рис. 2. Процентное соотношение различных фракций дерново-лесных почв

(пирогенный участок) в слое $0-5$ см

Реакция почвенной среды обуславливает скорость и направленность протекающих в почве химических и биохимических процессов. Установлена тенденция к росту значений $\mathrm{pH}_{\text {водн. }}$ (и $\mathrm{pH}_{\mathrm{KCl}}$.) в дерново-лесной глеево-элювиальной почве на следующий год (2011) после лесного пожара, произошло смещение показателя $\mathrm{pH}_{\text {водн. }}$ (и $\mathrm{pH}_{\mathrm{KCl}}$ ) от кислого - 5.21 (4.38) к слабокислому - 5.93 (5.09) диапазону на глубине 0-10 см под березняком, из-за того, что зола нейтрализует органические кислоты верхних почвенных горизонтов. В 2012 году отмечалась определенная стабилизация значений $\mathrm{pH}_{\text {водн. }}$ (и $\mathrm{pH}_{\mathrm{KCl}}$.) и стремление их значений к фоновым (рис. 3 ).

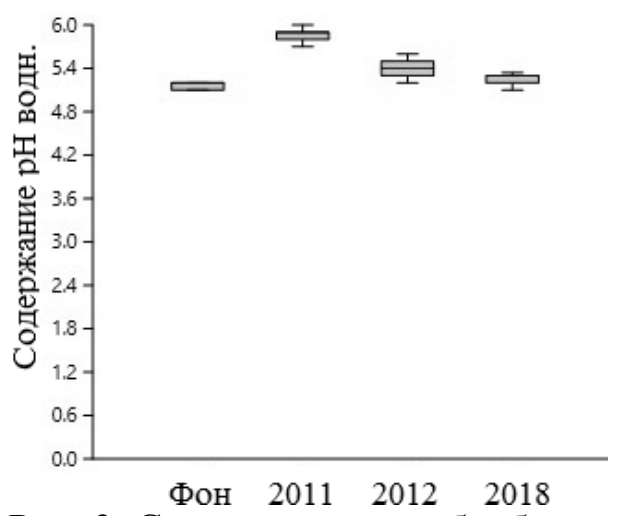

Рис. 3. Статистическая обработка результатов анализа $\mathrm{pH}$ водного в 0-10 см слое

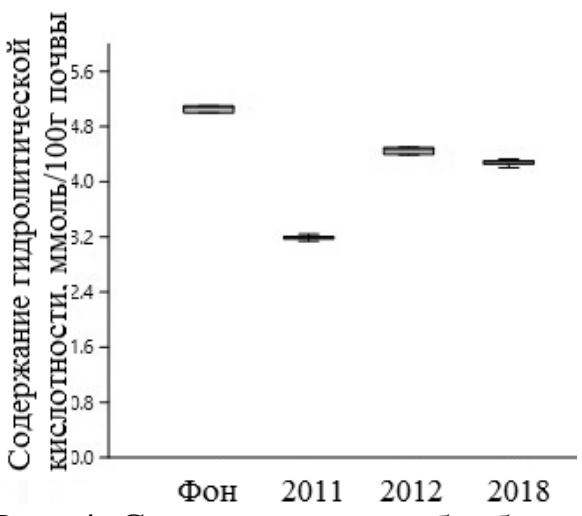

Рис. 4. Статистическая обработка результатов анализа гидролитической кислотности в $0-10$ см слое

$\mathrm{H}^{+}$- источник почвенной кислотности, присутствует всегда в бескарбонатных почвах, при $\mathrm{pH}$ от 6.5 до 7.2 присутствует в ПП в количествах менее 5\% (емкости катионного обмена) ЕКО, при более высоком содержании начинают проявляться кислотные свойства почв, тем в большей степени, чем выше доля $\mathrm{H}^{+}$в ППК, максимум кислотности достигается, когда доля водорода в ППК превышает 40-50\%, почва при этом становится кислой и сильнокислой (рН 3-5).

Гидролитическая кислотность обусловлена наличием ионов водорода, которые могут быть вытеснены из ППК катионами гидролитически щелочных солей. На- 
личие гидролитической кислотности указывает на начало процесса обеднения ее основаниями. На пирогенных почвах через год после лесного пожара (2011 г.) наблюдали снижение гидролитической кислотности, особенно в верхней части почвенного профиля по сравнению с не тронутой пожаром почвой. В дерново-лесной глеевоэлювиальной почве через год после лесного пожара гидролитическая кислотность снизилась на $38.2 \%$ (рис. 4), в 2012 году она увеличилась по сравнению с первым годом на 42.4\%. А к 2018 году гидролитическая кислотность уменьшилась по сравнению с фоновым показателем на $14.8 \%$.

Изменение в содержании гидролитической кислотности в сторону увеличения в последующий год, говорит о стремлении почвы как открытой системы к сохранению постоянства своего изначального внутреннего строения.

Таким образом, снижение гидролитической кислотности является следствием подщелачивания раствора верхних горизонтов исследуемых почв. В составе ППК основную долю составляют катионы кальция, а вторые позиции принадлежат катионам магния и поглощенному водороду гидролитической кислотности.

Изучая обменные катионы, можно отметить то, что пирогенный фактор оказал влияние на их содержание в сторону уменьшения, за счет перехода части обменных оснований в нерастворимую форму $\mathrm{CaCO}_{3}$. K 2018 году содержание обменных катионов $\mathrm{Ca}^{2+}$ и $\mathrm{Mg}^{2+}$ в слое 0-10 см под березняком сократилось на $8.7 \%$ относительно фоновых почв (от 8.99 ммоль(экв)/100 г почвы до 8.27 ммоль(экв)/100г почвы). По сравнению с показателями 2011 года содержание обменных катионов в 2018 году незначительно увеличилось (рис. 5).

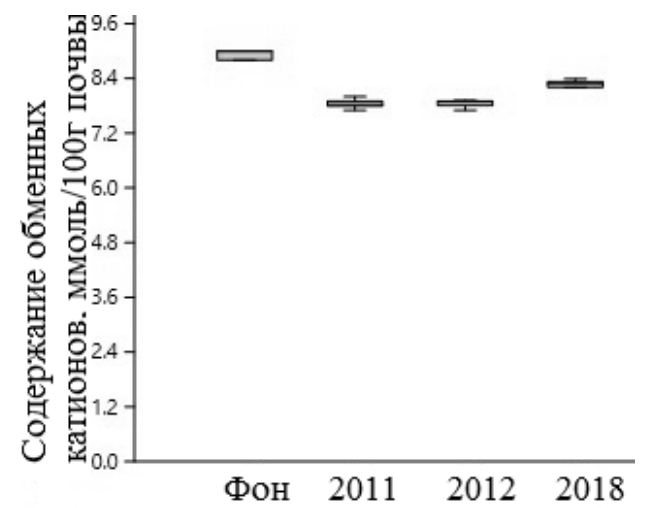

Рис. 5. Статистическая обработка результатов анализа содержания обменных катионов в 0-10 см слое

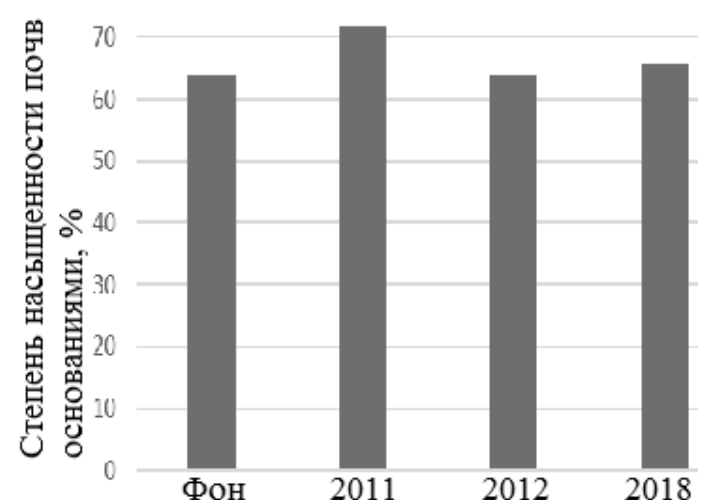

Рис. 6. Степень насыщенности почв основаниями в 0-10 см слое

$\mathrm{Ca}^{2+}$ присутствует во всех почвах, но в разных количествах и соотношениях с другими катионами, оптимальное содержание - 80-90\% ЕКО, способствует оструктуриванию, гумусообразованию, кислотно-основной буферности, способен к ионообменному поглощению корнями растений. Дерново-лесные почвы испытывают недостаток обменного $\mathrm{Ca}^{2+}, \mathrm{Mg}^{2+}-$ всегда сопровождает $\mathrm{Ca}^{2+}$, при увеличении доли в ППК вызывает повышение щелочности.

Расчет степени насыщенности исследуемых почв дает представление о том, какая часть общей емкости почвенного комплекса приходится на поглощенные основания, и какая на гидролитическую кислотность. Степень насыщенности основаниями в дерново-лесной глеево-элювиальной песчаной почве, после воздействия огня в 2011 году повысилась в слое 0-10 см на $13.3 \%$ из-за снижения гидролитической кислотности. В 2012 году степень насыщенности почв основаниями уменьшилась 
относительно первого года на $10.9 \%$, а в 2018 году стабилизировалась относительно 2012 года (рис. 6).

\section{Заключение}

Характер динамики ППК дерново-лесных глеево-элювиальных почв определяется ее низкой буферностью и низкой степенью насыщенности основаниями. По результатам исследования после лесного пожара содержание обменных катионов кальция и магния уменьшилось на $8.7 \%$ по сравнению с фоновыми почвами. По сравнению с показателями 2011 года содержание обменных катионов в 2018 году незначительно увеличилось. Подобное явление связано с тем, что дерново-лесные почвы обладают низкой способностью противостоять изменению реакции среды и низким эффективным плодородием, которое определяется родовыми и видовыми признаками, важнейшими из которых являются содержание гумуса, гранулометрический состав, физико-химические свойства и мощность почвообразующей породы.

\section{Список литературы}

1. Горбылева А.И., Воробьев В.Б., Комаров М.М. // Агрохимический вестник. 2008. № 1 . С. 6-9.

2. Ермолаев О.Т., Красницкий В.М. // Агрохимический вестник. 2012. № 4. С. 30.

3. Бузыкин А.И., Попова Э.П. // Продуктивность сосновых лесов. 1978. С. 5-47.

4. Громцев А.И. // Экология. 1993. № 3. С. 22-26.

5. Девятова Т.А.,, Горбунова Ю.С., Сорокина Н.A. «Physicochemical properties in the post-pyrogenic soils from the forests of Central Russia», Forestry 2018 : IOP Conf. Series: Eart and Environmental Science, 2019, p. 1-7.

6. Зайдельман Ф.Р., Шваров. А.П. Пирогенная и гидротермическая деградация торфяных почв, их агроэкология, песчаные культуры земледелия, рекультивация. М. МГУ. 200. 168 с.

7. Каплюк Л.Ф., Поляков А.Ф. // Почвоведение. 1980. № 8. С. 99-107.

8. Корчагин А.А. // Труды Ботанического института АН СССР, Сер. 3 (Геоботаника). 1954. вып. 9. М. С. 75-149.

9. Коршунов Н.А. // Сборник статей Ботанические исследования в Сибири. Красноярск. 2002. С. 153-158.

10.Краснощеков Ю.Н. // Почвоведение. 1994. № 9. С. 102-109

11.Краснощекова Е.Н. // Хвойные бореальной зоны. 2008. № 3-4. С. 250-255
12.Мелехов И.С., Душа-Гудым С.И., Сергеева Е.П. Лесная пирология. Москва, МГУЛ, 2007, 296 с.

13.Попова Э.П. Влияние низового пожара на свойства лесных почв Приангарья. Красноярск, 1975, С.166-178.

14.Сапожников А.П. // Экология. 1976. № 1. C. $42-46$.

15.Шапченкова О.А. // Почвоведение. 2011. № 6. С. 738-747.

16.Абрамс М.Д. // Растениеводство. 1992. №. 42. С. 346-353.

17.Арокена Дж., Опио С. // Геодерма. 2003. №. 113. C. 1-16.

18.Дебано L.F. // Гидрология. 2000. № 231232. С. $195-206$.

19.Энгелмарк О. // Журнал растениеводcmвa. 1993. №. 4. C. 791-794.

20.Джиованнини Дж. // Почвоведение. 1997. №. 162. С. 479-486.

21.Щеглов Д.И., Громовик А.И., Горбунова Н.С. Основы химического анализа почв. Воронеж. Издательский дом ВГУ. 2019. 332 с.

22.Дмитриев Е.А. Математическая статистика в почвоведении. М. МГУ. 1972. 292 с.

23.Доспехов Б.А. Методика полевого опыта (с основами статистической обработки результатов исследований). М. Агропромиздат. $1985.351 \mathrm{c}$.

24.Иванова С.А. автореферат. М. 1993. 26 c.

25.Чуян О.Г. // Агрохимия. 2010. № 10. С. 11-19. 


\section{References}

1. Gorbyleva A.I., Vorob'ev V.B., Komarov M.M., Agrohimicheskij vestnik, 2008. No 1. pp. 6-9.

2. Ermolaev O.T., Krasnickij V.M., Agrohimicheskij vestnik, 2012, No 4, pp. 30.

3. Buzykin A.I., Popova Ye.P., Produktivnost' sosnovyh lesov, 1978, pp. 5-47.

4. Gromcev A.I., Jekologija, 1993, No 3, pp. 22-26.

5. Devjatova T.A., Gorbunova Ju.S., Sorokina N.A. «Physicochemical properties in the postpyrogenic soils from the forests of Central Russia», Forestry 2018 : IOP Conf. Series: Eart and Environmental Science, 2019, pp. 1-7.

6. Zajdel'man F.R., Shvarov. A.P. Pirogennaja i gidrotermicheskaja degradacija torfjanyh pochv, ih agrojekologija, peschanye kul'tury zemledelija, rekul'tivacija, M., MGU, 2002, 168 p.

7. Kapljuk L.F., Poljakov A.F., Pochvovedenie, 1980, No 8, pp. 99-107.

8. Korchagin A.A., Trudy Botanicheskogo instituta AN SSSR, Ser. 3 (Geobotanika), 1954, vyp. 9, M., pp. 75-149.

9. Korshunov N.A. «Pozharoopasnost' lesov Nizhnego Priangar'ja», sbornik statej Botanicheskie issledovanija v Sibire, Krasnojarsk, 2002, pp. 153-158.

10.Krasnoshhekov Yu.N., Pochvovedenie, 1994, No 9, pp. 102-109.

11.Krasnoshhekova E.N., Khvojnye boreal'noj zony, 2008, No 3-4, pp. 250-255.

Горбунова Юлия Сергеевна - доцент кафедры экологии и земельных ресурсов Воронежского государственного университет, Воронеж, тел.: 8-951-856-25-98

Девятова Татьяна Анатольевна - профессор, д.б.н., зав. кафедрой экологии и земельных ресурсов Воронежского государственного университета, Воронеж
12.Melehov I.S., Dusha-Gudym S.I., Sergeeva E.P. Lesnaja pirologija, M., MGUL, 2007, 296 p.

13.Popova Ye.P. Vlijanie nizovogo pozhara na svojstva lesnyh pochv Priangar'ja. Krasnojarsk, 1975, p.166-178.

14.Sapozhnikov A.P., Jekologija, 1976, No 1, pp. 42-46.

15.Shapchenkova O.A., Pochvovedenie, 2011, No 6, pp. 738-747.

16.Abrams M.D., Rastenievodstvo, 1992, No 42, pp. 346-353.

17.Arokena Dzh., Opio S., Geoderma, 2003, No 113, pp. 1-16.

18.Debano L.F., Gidrologija, 2000, No 231232, pp. 195-206.

19.Jengelmark O., Zhurnal rastenievodstva, 1993, No 4, pp. 791-794.

20.Dzhiovannini Dzh., Pochvovedenie, 1997, No 162, pp. 479-486.

21.Shheglov D.I., Gromovik A.I., Gorbunova N.S. Osnovy himicheskogo analiza pochv, Voronezh, Izdatel'skij dom VGU, 2019, 332 p.

22.Dmitriev E.A., Matematicheskaja statistika v pochvovedenii, M., MGU, 1972, $292 \mathrm{p}$.

23. Dospehov B.A. Metodika polevogo opyta (s osnovami statisticheskoj obrabotki rezul'tatov issledovanij), M., Agropromizdat, 1985, 351 p.

24.Ivanova S.A. Avtoreerat, M., 1993, 26 p.

25.Chujan O.G., Agrokhimija, 2010, No 10, pp. 11-19.

Gorbunova Yuliya S. - docent, the laboratorian of faculty of ecology and ground resources of the Voronezh state university, Voronezh, gorbunova.vsu@mail.ru

Devyatova Tatyana A. - managing chair of ecology and land resources of the Voronezh state university, the professor, Doctor of Biological Science, Voronezh, devyatova@bio.vsu.ru 